\title{
LESSONS LEARNED: ONLINE TEACHING ADVENTURES AND MISADVENTURES
}

\author{
Phillip Fuller and Geungu Yu
}

Department of Economics, Finance and General Business, Jackson State University, Jackson, MS USA

Received 2014-03-28; Revised 2014-04-22; Accepted 2014-04-24

\begin{abstract}
This study provides practical "nuts and bolts" advice on developing and teaching a new online course for first-time online instructors. The advice is predominantly based on the observations and experiences of two instructors who developed and taught online courses for the first time on the "maiden voyage" of a newly established online MBA program and subsequent online teaching experiences. The lessons learned the "hard way" are discussed so instructors who are developing and teaching online courses for the first time within the context of a new program can avoid some "learning curve" problems.
\end{abstract}

Keywords: Online Teaching, Distance Learning, Textbook Selection, Cheating, Communicating with Students

\section{INTRODUCTION}

How students are taught is changing. Courses are still offered in classrooms using the traditional chalk and talk lecture method. However, courses are increasingly being infused with web-based technology. Some instructors teach hybrid courses which require some face-to-face contact with their students and to varying degrees; these instructors may require that homework, examinations and/or other assignments be completed online. Online courses are increasingly being taught without the physical presence of teachers and the students complete all assignments, homework and examinations online and submit term projects by e-mail.

Web-based technology may enhance instructors' abilities to teach courses while simultaneously enriching their students' learning experiences. Webbased learning enviroments normally include learning content delivery tools such as: Synchronistiic and nonsynchronistic conferencing sysytems, quiz modules, grade reporting systems and creation of virtual classrooms (Baseera and Srinath, 2014). Nonsynchronistic conference systems include the use of: Hypertext, emailing, mailing lists, file downloads and discussion groups. Synchronistic conference systems include the use of: Chatrooms, whiteboard, audio-video streaming, video conferences and virtual classrooms (Abdellatief et al., 2011; Al-Dosari, 2011).

Infusing web-based technology into courses enables: Instructors to better monitor students' study habits and performance and provide students with timely feedback on assignments, quizzes and major examinations. Instructors are apt to be more thoughtful when preparing their syllabi and they can also upload materials to help equalize coverage of course materials in all their classes (Pattanasethanon and Chanthinok, 2013). Utilizing webbased technology to supplement the traditional classroom lectures may allow more "free time" in classes. The additional free time can be used to increase a course's breadth and/or depth.

Some students find distance online courses and programs more accessible and more desirable. Since webbased courses can be taken by students asynchronistically, the impacts of geographic and time constraints are lessened since students can access the internet through personal computers and other mobile devices. Alzaza and Yaakub (2011) believe in the future that the use of mobile devices will become students' preferred technology when they take online courses.

Students' flexibility in managing their time as it relates to work, family and other social obligations is increased when they take online courses. Some students Corresponding Author: Phillip Fuller, Department of Economics, Finance and General Business, Jackson State University, Jackson, MS USA 
enroll in online courses due to timing conflicts with other needed courses, or due to illness or physical limitations. When the costs of transportation are increasing and some families must deal with lower household incomes due to unemployment and/or underemployment, students who normally commute may also prefer online courses. Online courses and programs may lower students' total cost by eliminating and/or reducing commuting, childcare and other expenses.

Online courses have some potential drawbacks. Online students may feel a sense of isolation if they lack face-to-face interaction with other students and their instructors. Feeling isoloted can negatively impact a student's ability to learn. Students who feel a sense of connectiveness and psychological closeness are more apt to achieve higher-order thinking and knowledge building (Baker, 2010; Yen, 2013).

Taking online courses at home may expose students to a variety of household distractions, such as: Family and friends, pets, the call of the refrigerator and other procrastination devices (Zabriskie and McNabb, 2007). Some students may lack the required discipline and skills to sucessfully complete online courses. Al-Dosari (2011) stated that online students are expected to: Act with initiative and enthusism; reason effectively and creatively with an integrated, flexible, usuable knowledge base; and monitor and assess their own ablities to achieve desirable outcomes.

Universities offer online courses and programs to increase enrollment and educational attainment for students and the local populace. In states where universities' funding is based either on enrollment and/or credit hour production, offering online courses may enhance universities financially. Furthermore, some university administrators believe offering online courses is necessary to sustain a competitive advantage in an increasing competitive market (Gibson et al., 2008).

Despite the benefits that providing access to online courses and programs generate, universities expose themselves to risk. Universities need to provide financial support to purchase and maintain the necessary technological infrastructure and must acquire and marshal human resources to offer online courses. For example, libraries need additional funding to provide more digitized materials to online students so their educatinal attainment will be on par with tradional students (Diaz, 2012). If the online courses and programs are not properly marketed, managed, developed and taught, online efforts could become a financial drain and a public embarrassment. Universities' online initiatives can be negatively impacted by factors out of their control such as: The economy, competition from other universities and funding from the state legislature.

According to the The National Center for Education Statistics (NCES, 2011) in the 2007-2008 academic years, $20 \%$ of undergraduates were enrolled in at least one distance education class, an increase from $8 \%$ in the 1999-2000 academic year. Four percent of undergraduate students in the 2007-2008 academic year were enrolled in degree programs that were taught entirely as distance learning-an increase from $2 \%$ in the $1999-2000$ academic year. Computer and Information Science claimed the highest enrollment percentage in distance learning courses (27\%) and degree programs (8\%). Business achieved the second highest enrollment percentage in distance learning courses (24\%) and degree programs (6\%). Tanner et al. (2009) reported that of the business disciplines, Accounting and Finance faculty taught the highest percentage, $18 \%$, of distance learning classes.

NCES (2008) reported that approximately $66 \%$ of two-and-four-year Title IV degree-granting institutions offered distance learning courses. NCES also reported that $92 \%$ used asynchronistic internet-based technology and $32 \%$ used synchronistic internet-based technology. The third most frequent delivery system, with $23 \%$, was two-way interactive video. Moreover, providing students with the opportunity to take online courses can be a winwin situation for both students and universities.

\section{PURPOSE}

Most articles on distance learning can be placed in one of two categories: (1) Perceptions of web-based teaching and (2) teaching pedagogies. This study does not fit perfectly into either category. This study's purpose is to provide practical "nuts and bolts" advice on developing and teaching a new online course to first time online teachers. The advice is predominantly based on the observations and experiences of two instructors who developed and taught online courses for the first time on the "maiden voyage" of a newly established online MBA program and subsequent online teaching experiences.

\section{BACKGROUND}

The College Of Business (COB) at a regional university decided to offer an online MBA. The purposes of the program were twofold: (1) Increase graduate enrollment and (2) help the university generate additional revenue. Students who enrolled in the online MBA were required to meet the same admission requirements as students in the traditional MBA program. 
We decided to teach our courses to increase our income and retirement benefits and improve our vitae. (To enhance the readability of this study, "we" is sometimes used to refer to one of the authors. In most cases, "we" is used as a traditional plural pronoun). The improvement in the vitae was perceived as a career-enhancing move that would increase our chances of becoming double-dippers. Additionally, preparing and developing online courses offered us new learning experiences. Furthermore, it was felt that using this experience would help us to enrich our more traditional classes by infusing web-based assignments into our traditional classes.

\section{ADVENTURES AND MISADVENTURES}

We were scheduled to start teaching our online courses at the beginning of spring semester. In the beginning of the fall semester, we voluntarily participated in Blackboard training sessions. In the last few weeks of the fall semester, we participated in a mandated four week online training session that focused on Ecollege and teaching online.

In December, we began developing our respective graduate courses: Managerial Finance and Investments using Ecollege. At that moment, we realized that our training sessions had taught us several strategies and pedagogical approaches on teaching an online course, but not how to actually develop one.

We realized that the Ecollege system differed from Blackboard. In fact, we discovered that several other online course management systems existed. Based on exploration of the Ecollege course shells, we were able to ascertain how to develop course trees and to establish the time-lines for our courses. Some of the knowledge obtained from the Blackboard seminars was useful in course development using Ecollege. Due to time constraints, the December winter recess period was utilized to develop our courses.

Consequently, we experienced a lot of anxiety and frustration; these feelings could have been reduced or eliminated with a clearer initial understanding of the purpose of our training. Knowing the purpose of the training would have motivated us to ask more specific questions about how to develop an actual course and we would have started to develop our courses sooner. Individuals developing courses should start developing courses sooner, rather than later, to avoid being rushed and feeling anxious and/or frustrated.

Support staff and colleagues who have developed and/or taught online courses are good sources of information and assistance. Getting advice from others may be more efficient and effective and less frustrating than reading and searching through the reams of documentation and/or using the "Help" tab when developing an online course.

Selecting an appropriate textbook is one of the most critical decisions in developing and teaching an online course. Online students may have a more diverse academic background than traditional business students. Consequently, in some cases the textbook used in the traditional classroom setting may be inappropriate for an online course. This inappropriateness may stem from students' limited exposure to basic business courses. For example, most students in a traditional MBA program tend to have an undergraduate business major while some students in an online MBA program may have nonbusiness undergraduate degrees in science, health care, education, public policy, or engineering.

Disparities among textbooks exist when it comes to their usefulness among traditional, technologyinfused, hybrid and/or online classes. Some textbooks have more and/or better supplemental materials that can be accessed online, such as homework problems, assignments, test banks and eBooks. The usefulness of the supplemental materials is influenced by the professor's ability to establish policies as to when assignments are to be completed and to what extent the course management system grades assignments and provides feedback to students.

The compatibility of a book's course management system with the university's course management systems should be considered when selecting a textbook. For example, some publishers offer supplemental materials that can be loaded into Blackboard, Ecollege and/or other course management systems. Textbook sales reps, staff and colleagues can help to identify textbooks that satisfy compatibility requirements.

Once a textbook is selected, it may not be necessary to download assignments and test banks into the university's course management system. One sales rep stated that a book under review was compatible with Ecollege, while another sales rep stated that his company's book was not compatible with Ecollege. We chose the books that were compatible with Ecollege. But, after reviewing the textbooks' online assignments, test banks and eBook, we decided it was quicker and more convenient to provide students with instructions on how to access our books' website in order to complete most textbook assignments and tests. Instructors should be aware of requirements and/or limitations, if any, that a university's policies place on the use of online materials. 
Whether or not a publisher provides textbooks with grace periods that allow students to access online materials before licensed access is purchased should be considered. Students may need immediate access to all online materials, but due to financial difficulties, students may delay purchasing licensed access of web-based materials. Students' financial difficulties may become more pronounced as: (1) Pell Grants become less accessible; (2) universities increase tuition and other fees; (3) funding reductions of universities may cause staffing shortages, along with snafus, that may increase the wait-time before students receive their financial aid; and, (4) the economy could adversely impact students' families financially. These factors, along with others, may cause students to delay purchasing access to webbased materials. The delays in purchasing access to web-based materials will probably be more pronounced at universities whose student body tends to come from lower income families.

The benefits of the grace period can be easily overlooked. When an incorrect ISBN number was provided, the requested book did not include an access code to the online material. However, students were still able to complete online assignments during the grace period. Before the grace period ended, the sales rep ultimately resolved the problem by providing a free master code so the class could continue to access online materials. The code was provided as a "trial offer" since we had never used any of the publisher's web-based materials. When ordering textbooks for a class that is part of a new program, instructors should determine whether the book-ordering process has been altered (our process was changed) and should make certain the correct textbook package is ordered.

Throughout the course, students were required to complete chapter quizzes and mid-term and final examinations online. Students were encouraged to print the chapter quizzes and to answer questions as they read each chapter. They were instructed to view the chapter quizzes as reading assignments instead of homework problems. Quizzes were constructed to force students to read each chapter from beginning to end. After reviewing the time stamps, it was apparent that students were attempting to complete the end-of-chapter problems prior to reading the assigned chapter. A memo was emailed to students, instructing them to read each chapter and complete the quiz prior to completing the end-of-chapter homework problems.

Viewing the time stamps and perusing submitted assignments enables instructors to identify students who may be having problems and/or may not be devoting adequate time to the course material. Providing students with the PowerPoint slides and the solutions to all endof-chapter questions and problems may help students to learn the material. Biktimirov and Klassen (2008) mentioned that offering the solution to students online was positively related to student performance.

During the course, students were also required to respond to discussion questions. By reviewing the time stamps, we discovered most of the students responded to the discussion questions prior to reading the assigned chapter. They were reminded and advised to read the chapter before responding to discussion questions and fellow students' comments.

Midterm and final examinations were for the most part non-eventful. However, one student claimed inability to complete a test in the required time period because a snow storm had knocked out his electricity and internet connections. Based on The Weather Channel, the entire continental U.S. had clear skies on that date, except for a winter storm in the specific part of the state where this student resided. Today's technology allows access to immediate weather reports which can be used to verify, to a certain extent, a student's reported inability to complete assignments due to inclement weather.

Academicians tend to believe that students in online courses are more apt to cheat than students in traditional face-to-face courses (Miller and YoungJones, 2012). Miller and Young-Jones (2012) discussed research that found that online students cheated less than traditional students. They also discussed research that found that online students cheated more than traditional students. Miller and Young-Jones (2012) own research found that students who took: (1) Both online and traditional face-to-face courses cheated more in online courses and (2) only online courses cheated less than students who took only traditional face-to-face courses. They believed their findings were attributed to older students' tendency to take online courses.

Watson and Sottile (2010) provided evidence that cheating in online courses was no more rampant than cheating in traditional face-to-face classes. However, evidence was provided that online students were more apt to obtain answers from others during an online test or quiz. Watson and Sottile (2010) believed that lowering the weights of online quizzes and tests and requiring more essay questions, which would necessitate a more in-depth understanding of the material in order to answer questions and to severely penalize cheaters, would reduce cheating behavior. 
The potential for students to engage in inappropriate behavior such as: Cheating, plagiarism and other misrepresentations is a major limitation to teaching online. Students today have a different definition of academic dishonesty than prior generations (Conway-Klaassen and Keil, 2010). Students can be discouraged from engaging in inappropriate behavior: Instructors can establish guidelines, explaining what behavior is appropriate and what behavior is inappropriate. Instructors can tell students that their activities will be monitored (even if the monitoring is very limited). Conducting open-book tests and placing time constraints on the examinations helps to reduce inappropriate behavior (Christe, 2003). Conway-Klaassen and Keil (2010) recommended: Developing alternative tests; randomizing questions and answers; displaying one question at a time; and denying students the ability to: Look at previous questions and print tests; and revealing scores and answers only after the test is closed to all students.

Communications with students can take many forms and can help students to feel engaged and not isolated. Students are provided syllabi, instructions on assignments and announcements. Students also receive feedback on tests, assignments, discussions and questions. When providing students instructions and/or feedback, using a larger font than normal may be beneficial. Some students may face visual challenges. Using a larger font may help instructors avoid typographical, grammatical and other errors. When proofreading, the larger font makes it easier to detect errors.

We also capitalized, underlined, italicized, or bolded and/or colored some select words to add emphasis when communicating with students. Whenever possible we added some personal tidbits or humor to make communications more lively, which hopefully made the students feel less isolated. We also used emoticons. Emoticons are usually easy to interpret and can act as online facial expressions that enhance online comunications (Al-Zhrani, 2010).

When emailing students, we recommend that instructors ask students to respond by composing new messages rather than just replying to the instructors' emails. We inadvertently overlooked some correspondences and attachments when several students replied to the same email.

Instructors should develop a mailing list for their online courses. Due to bad weather, technical difficulty, or routine maintenance, instructors may not be able use the university's course management system to communicate with students. Consequently, instructors should create course mailing lists that are accessible without using the university's course management system.

Developing an online course can take hundreds of hours. Creating, maintaining and updating a folder specific to each online course is recommended. The folder can be used to store backup and other important files. The folder can be used to reconstruct a course that has been accidentally deleted, changed, or lost. The folder can be used to replace damaged or lost modules and files. The folder is also a good place to save files and other information that can be added to the course at a later date. Feedback and instructions to students from one class to another may be somewhat similar. Saving this information will help to reduce the amount of time used communicating with students and hopefully improve the quality of the course each time it is taught.

\section{CONCLUSION}

This study was written to provide practical recommendations to aid others in their efforts to develop and/or teach online courses. The information provided can be used also by instructors who desire to teach hybrid courses and/or to infuse web-based materials into their courses. Course management systems provide means to monitor students and to grade assignments and quizzes. Consequently, we hope that students will be more motivated and apt to read assigned chapters and to complete homework assignments in a timely manner.

Students can be provided a variety of teaching materials such as: PowerPoint slides, lecture notes, homework solutions and web-sites to enrich their learning experience. Although students may not feel the need to use all the supplemental material, students certainly can pick and choose among the materials that best satisfy their own learning style and needs.

Instructors' best source of assistance when developing a course are colleagues who can provide insight into what is working and not working. Since each group of students may have different backgrounds and skill-sets, colleagues can provide valuable information concerning the students' academic backgrounds and work habits as they matriculate through a program.

Book reps easily can be an overlooked resource; they are familiar with the assortment of textbooks, supplemental materials and course management systems. Book reps also are aware of the grace period offered for textbooks. The university's and publishers' technical support staffs can aid in developing a course and overcoming technical issues. Finally, make a folder to save important files that can be used to reconstruct and/or update the online course. 


\section{REFERENCES}

Abdellatief, M., A.B.M. Sultan, M.A. Jabar and R. Abdullah, 2011. A technique for quality evaluation of e-learning from developers perspective. Am. J. Econ. Bus. Admin., 3: 157-164. DOI 10.3844/ajebasp.2011.157.164

Alzaza, N.S. and A.R. Yaakub, 2011. Student's mobile information prototype for the higher education environment. Am. J. Econ. Bus. Admin., 3: 81-86. DOI: 10.3844 /ajebasp.2011.81.86

Al-Dosari, H., 2011. Faculty members and students a project evaluation. J. Soc. Sci., 7: 391-407. DOI: 10.3844/jssp.2011.391.407

Al-Zhrani, S., 2010. A structural study between chatting and cheating. Am. J. Applied Sci., 7: 1358-1363. DOI: 10.3844/ajassp.2010.1358.1363

Baker, C., 2010. The impact of instructor immediacy and presence for online student affective learning, cognition and motivation. J. Educators Online, 7: 1-30.

Baseera and Srinath, 2014. Design and development of a recommender system for e-learning modules. J. Comput. Sci., 10: 720-722. DOI: 10.3844/jcssp.2014.720.722

Biktimirov, E.N. and K.J. Klassen, 2008. The relationship between use of online support material and student performance in an introductory finance course. J. Educ. Bus., 153-158. DOI: 10.3200/JOEB.83.3.153-158

Christe, B., 2003. Designing online courses to discourage dishonesty. Educ. Q., 26: 54-58.

Conway-Klaassen, J.M. and D.E. Keil, 2010. Discouraging academic dishonesty in online courses. Clin. Lab. Sci., 13: 194-200. PMID: 21140791

Diaz, C., 2012. Academic library services to distance learners: In consideration of costs, technology and stablity. Urban Library J.
Gibson, S.G., M.L. Harris and S.M. Colaric, 2008. Technology acceptance in an academic context: Faculty acceptance of online education. J. Educ. Bus., 83: 355-359. DOI: 10.3200/JOEB.83.6.355-359

NCES, 2011. Learning at a distance: Undergraduate enrollment in distance education courses and degree programs. U.S. Department of Education, Institute of Education, Sciences National Center for Education Statistics.

NCES, 2008. Distance education at degree-granting postsecondary institutions: 2006-07. NCES.

Miller, A. and A.D. Young-Davis, 2012. Academic integrity: Online classes compared to face-to-face classes. J. Instruct. Psych., 39: 138-145.

Pattanasethanon, P. and K. Chanthinok, 2013. An evaluation of the information systems for teaching and learning online of the public university. J. Comput. Sci., 9: 114-121. DOI: 10.3844/jcssp.2013.114.121

Tanner, J.R., T.C. Noser and M.W. Totaro, 2009. business school administrators' and faculty perceptions of online learning: A comparative study. Issues Innovat., 3: 93-112.

Watson, G. and J. Sottile, 2010. Cheating in the digital age: Do students cheat more in online courses? Online J. Distance Learn. Admin.

Yen, A.C., 2012. Social interactions for academic purposes in literature classes for non English speakers. J. Soc. Sci., 8: 412-419. DOI: 10.3844/jssp.2012.412.419

Zabriskie, F.H. and D.E. McNabb, 2007. E-Hancing the Master of Business Administration ('MBA) managerial accounting course. J. Educ. Bus., 82: 226-232. DOI: $10.3200 / J O E B$ 